\title{
Challenges to the Professional Practice of Architects in China Under the Trend of Globalization
}

\author{
Xunmei $\mathrm{Wu}^{1}$ \\ ${ }^{1}$ Huazhong University of Science and Technology, Wuhan, China \\ Correspondence: Xunmei Wu, Huazhong University of Science and Technology, Wuhan, China.
}

Received: June 26, 2019

Accepted: July 22, 2019

Online Published: July 23, 2019

doi:10.20849/ajsss.v4i2.612

URL: https://doi.org/10.20849/ajsss.v4i2.612

\begin{abstract}
With the globalization of the economy, culture and information, all kinds of social forms are changing, and the process of modernization is bound to be strongly influenced by international trends. Under this background, this paper attempts to discuss the challenges of globalization to our architects by presenting the positive and negative situations of globalization.
\end{abstract}

Keywords: globalization, architects, challenges and opportunities, cross-culture

\section{Introduction}

Rapid urbanization and technological advances have made modern buildings more and more standardized, which has deprived residential areas of cultural and regional identity. In this case, the trend of standardization has become worldwide discomfort with the application of the same building methods, materials and styles. Architectural art is always the most important item on the agenda of many conferences, which are looking for ways to bring about a better and fairer city. In recent years, global cities and globalization have become key concepts for social scientists, architects and economic geographers to observe, experience and describe the profound changes brought about by new technologies to global economic and spatial development. Planners quickly followed the academic orientation, trying to explore ways and means to extend urban areas to world cities, and architects then analyzed and criticized the negative impact of globalization on local and regional areas. Areas exist not only on maps, but also in people's minds and memories. When a particular place brings an experience, evokes associations or memories, its identity becomes interesting. In this context, this paper attempts to demonstrate the positive and negative potential of globalization through case studies, while encouraging the importance of adapting to globalization, and analyze the challenges that globalization trends pose to Chinese local architects.

Because of globalization, cities and regions are facing enormous challenges. The word "globalization" was coined in the second half of the 20th century, but it was not until the second half of the 1980s that the word "globalization" and its concept penetrated into the public consciousness (Chris, 2006). As a popular word in the past decade, globalization has attracted more attention than other issues. Giddens defines globalization as the strengthening of global social relations, which connect distant places in a way that local events are formed by events that occur miles away, and vice versa. In this sequence, globalization is regarded as a kind of repeated exposition of knowledge, which improves people's understanding of the links between different life scales. The Encyclopedia Britannica defines globalization as a process of standardizing everyday life experiences around the world (Adam, 2008). The tension between anti-globalization forces and pro-globalization forces has a long history, and the two opposing forces affect the construction globalization. A force is trying to protect and disseminate the established local architectural traditions, forms, decorative patterns and techniques. It advocates historical continuity, cultural diversity and identity preservation, all of which are symbolized by a specific architectural vocabulary, just like the regional identity given by spoken language and local dialects. Another force uses new technologies and materials to promote new forms of invention and dissemination in response to changing functional needs and sensitivities. It focuses on systematization, flexibility and interchangeability (Lewis, 2002). For some, globalization means westernization of the world. Some people think that globalization has produced more and more homogeneity, while others think that globalization has produced diversity and heterogeneity through hybridization.

The biggest and most prosperous architectural practice in the world is in China. On the one hand, globalization 
provides opportunities for China's architectural practice. Whether you like it or not, it represents the most advanced efficiency, and it is also the closest to people's life and production. On the other hand, I think that the impact of globalization for Chinese architects, mainly in three aspects: technical and cultural aspects and their own status.

\section{Challenges of Technology and Engineering}

To be sure, in the past few decades, the world has been experiencing the most important period of technological innovation and global restructuring since the first decades of the 20th century. Cities have always been the center of civilization and vitality. Over the years, material and scientific progress has made human progress. Globalization is now an irresistible historical process dominated by technological change, involving the dissemination of science and new technologies. Rapid urbanization can only be achieved by introducing modern technology into the process of development. In an ancient architectural paper, Vitruvius put forward three basic requirements for all excellent buildings: firmness, practicality and aesthetics (Mogan, 1914). In order to guide the quality of the building, we should consider the technical means, the practicability and function of the building as well as the aesthetic effect. Auguste G. Perrett also defined architecture as a living art, faithfully expressing and visualizing its era through the expression of contemporary architectural technology (Schoon, 1992). Complex architecture and advanced architecture design require mastery of structure and construction technology. As Michelle Addington said, "Technology is usually considered as the servant of design, so it is considered subordinate: why design is, what it is, and how technology is achieved." New technology suspends the essence of work and its multidimensional effects by creating new forms of leisure, including surrealism in cyberspace, new virtual reality and new information and entertainment modes. For centuries, dramatic change and innovation have been part of modernity, as have technological development and expansion. Thanks to computer and communication technology, a new global culture is emerging. Architectural forms are crossing national boundaries and becoming part of the culture of the new world. The wave of new technologies in the fields of electronics, robotics, telecommunications, new materials and biotechnology has spawned a new technological paradigm, emphasizing the role of world cities (Yeung, 1998). Therefore, the adoption of appropriate technology is a natural and non-compulsory consequence of an appropriate architecture. Together, they provide effective forms and images to replace the models provided by industrialized countries. As Shahin Vassigh said, "Architectural practice is a delicate balance between art and Science - a creative effort that also requires architects to master a wide range of technical skills, including engineering technology."

\section{The Impact of Cultural Heterogeneity}

In the past few years, globalization has become a popular phrase in architecture, which is related to the loss of location labels. It seems to be generally accepted that identity plays an important role in the continuation of human culture; otherwise, he will be cut off from the past. Local identity is attracting more and more interest from architects and planners, as well as social science research. The term "place identity" conveys many different dimensions, such as physical size, tangibility and symbolism, known and experienced and unknown or inexperienced.

In many contexts, localization is politically correct, aggressive and defensive. Entering can be globalization, because "the nation is the world, the native is the global"; retreating can be cultural conservatism, emphasizing local values, local art and local customs. As designers of the elite stratum, most of them show respect, understanding and recognition to localization in varying degrees. Rich and colorful regional differences provide designers with extensive and profound creative inspiration.

At present, western architecture attracts people's attention rapidly. Chinese architects, while pursuing and learning the reinforced concrete structure in Western architecture, will disappear the buildings with traditional Chinese cultural characteristics. Chinese people blindly pursue foreign cities, architecture, art and fashion, attach too much importance to foreign architectural works and ideas, and ignore or even despise domestic architectural culture, which has a great negative impact on domestic architectural creation.

Globalization has gradually evolved the new vision of promoting economic and cultural exchanges among countries into the criteria and yardsticks for measuring their economies and cultures. The field of architecture has not escaped the fate of being standardized. While the art of architecture is unpredictable, there are also many problems, such as the contradiction between the rapid renewal of the aesthetic trend of architecture and the "eternity" pursued by culture and art, the horizontal and vertical contradiction of architectural culture, the contradiction between the rapid development of science and culture and art, and the contradiction between traditional culture and modern culture. As can be seen from the actual national conditions, it is in the stage of embracing foreign architecture in an all-round way. Architecture naturally becomes a commodity, reflecting the 
aesthetic and values of foreign countries. Facing various, complex and overwhelming architectural trends, Chinese people are likely to be overwhelmed by this strong trend.

Some people may think that foreign architects do not fully accept Chinese traditional architectural culture, or that some Chinese owners do not like buildings with Chinese characteristics. However, we also have to admit that the research and exploration of Chinese traditional architectural culture has been put on the shelf and is vulnerable and passive. The buildings with Chinese traditional characteristics are disappearing day by day, leaving behind only some irreparable regrets.

For architects, focusing on the study of traditional culture is not a boycott of contemporary culture. Traditional culture is a clear spring with a long history, which conforms to the pace of the development of the times. Architecture is the silent representative of the national spirit. If we want to inherit the traditional culture, we should avoid blindly imitating it or pushing back the reconstruction in the traditional way. These are all irrational practices. We should attach great importance to history and culture and truly realize the combination of tradition and modernity. At present, people often attach great importance to the surface form of architecture, which leads to over-emphasis on form and eager for quick success and instant benefit in the field of architecture. Blind and arbitrary use of historical symbols simplifies tradition into symbols, pursuing only visual aesthetics but ignoring the deep meaning of works.

Professor Liu Zong, a Chinese architect, has made classical comments on ancient Chinese architecture. He believes that the reason why ancient Chinese architecture has shocking artistic charm is not the form of large roof glazed tiles used in ancient Chinese architecture, but the integration of Chinese philosophy, environmental awareness and space concepts into ancient architecture. The fundamental reason why Chinese ancient architecture has artistic charm lies in. Therefore, in the process of architectural creation, architects should not only take the material resources of traditional buildings as inspiration and inspiration, but also consider the deep meaning hidden in the architectural culture and pay attention to the excavation of traditional spiritual materials. This view is also what Mr. Pei has insisted for 30 years: "Architects who always want to express Chinese spiritual beliefs".

Therefore, we realize that history and culture should not only be the end of the old events or fragments, but also exist in an invisible spiritual outlook. At this time, the "invisible is better than tangible" traditional culture should be endowed with its traditional, regional and national spiritual civilization, thus reflecting its unique traditional charm.

\section{The Deviation of Architect's Orientation}

Architects shoulder too many expectations and are given too many responsibilities. Therefore, this era should give them more rights. At this stage, the social status of domestic architects is relatively low, it is difficult to have independent and due decision-making power, and the process of architect's creation will be disturbed. Therefore, how to enhance the status of architects and increase their independent decision-making rights is a topic worthy of discussion. In my opinion, efforts can be made from the following aspects: first, architects need to strengthen their own professional competence, strive to enhance professional accomplishment, strengthen the understanding of architecture, so that they can have a deep understanding of technology and culture, have the ability to capture the trend of architectural creation keenly, and lay a solid foundation for creative architectural creation. Second, architects need to expand their theoretical achievements and gradually accumulate a solid academic foundation. This process requires a good ability to distinguish and prevent their blind absorption. Only with a solid professional foundation can architects have their own creative language in the process of architectural creation, and have more confidence in local architectural design. This is also the process of re-perfection and evolution of Chinese-style survival concept and environmental order. In a word, society should establish enough respect for architects and architectural culture. Only in this way can the development space of Chinese architectural culture be more open and attractive. Architects shoulder the responsibility entrusted by society. The premise of fulfilling the responsibility is to improve their professional accomplishment and to have a thorough understanding of the local culture. In order to avoid the phenomenon of "aphasia", apart from advocating respect for traditional culture and giving traditional due status, it is also necessary to advocate the development of architects' personality. Of course, personality development is based on context and regional environment. It is imperative to enhance the independent decision-making power of architectural creators.

Under the background of globalization, only by facing these challenges correctly, can the architectural practice in China continue with its own characteristics? Any single choice about localization and globalization of architecture is wrong and harmful to the development of Chinese architectural art. If China wants to be open, an open nation is a hopeless one; if architecture wants to communicate, architecture without communication is a 
hopeless one; the most important thing is for architects to learn, to face challenges correctly and bravely, and architects who do not distinguish right from wrong are equally hopeless. In the process of interaction between localization and globalization, China's architectural practice has gradually improved, seeking new possibilities and building modernization.

\section{References}

Adam, R. (2008). Globalisation and architecture: The challenges of globalisation are relentlessly shaping architecture's relationship with society and culture. The Architectural Review, 223(1332), 74-77.

Addington, M. (2006). Functionality rather than good intentions in design. Journal of Architectural Design, $76(1), 64$.

Doratli, N., Hoskara, S. O., Vehbi, B. O., \& Fasli, M. (2007). Revitalizing a declining historic urban quarter The walled city of Famagusta, North Cyprus. Journal of Architectural and Planning Research, 24(1), 65-88.

\section{Copyrights}

Copyright for this article is retained by the author(s), with first publication rights granted to the journal.

This is an open-access article distributed under the terms and conditions of the Creative Commons Attribution license (http://creativecommons.org/licenses/by/4.0/). 